\title{
Klasifikasi Opini Terhadap Pertanian Sawit (Palm Oil) Indonesia Menggunakan Naïve Bayes
}

\author{
Hafiz Irsyad $^{1}, M_{\text {Rizky Pribady }}^{2}$ \\ ${ }^{1,2}$ STMIK Global InformatikaMDP; Jl. Rajawali No. 14 Palembang Sumatera Selatan, Telp: \\ (0711) 376400 \\ e-mail: *1 hafizirsyad@mdp.ac.id, ${ }^{2}$ rizky@mdp.ac.id
}

\begin{abstract}
Abstrak
Dalam tiga tahun terakhir ini produksi pertanian sawit dinilai sangat meningkat. Indonesia merupakan negara penyumbang sawit terbanyak. Bersama Malaysia yakni 85-90\% dari total keseluruhan hasil sawit dunia. Dengan banyaknya informasi terhadap sawit Indonesia di twitter sehingga dapat dimanfaatkan untuk melihat opini masyarakat tentang sawit Indonesia. Pada penelitian ini berhasil mengumpulkan data tweet dari 28 Agustus 2019 sampai dengan 21 Juni 2018 menghasilkan 1015 tweet. Agar bias melihat tweets tersebut maka dikelompokan perkategori menjadi positif, negatif dan netral, kemudian tweets tersebut diklasifikasikan dengan menggunakan metode nä̈ve bayes dan menggunakan tools Orange. Sedangkan untuk melakukan crawling data memanfaatkan fasilitas API Twitter. Dari 1015 data tweets tersebut $70 \%$ digunakan untuk data training dan 30\% untuk data testing. Dalam penerapan kalisifikasi dengan metode naïve bayes ini menghasilkan akurasi rata-rata akurasi $0.83337 \%$ untuk rata-rata seluruh kategori, untuk precision memperoleh $0.80303 \%$ untuk ratarata seluruh kategori, dan untuk recall menghasilkan $0.90853 \%$ untuk seluruh rata-rata kategori. Dengan tingkat akurasi tersebut metode naïve bayes berjalan sesuai dengan harapan.
\end{abstract}

Kata kunci-Naïve Bayes, Sawit Indonesia, Opini, Klasifikasi

\begin{abstract}
Last three years the production of oil palm agriculture has been considered to have increased significantly. Indonesia is the largest contributor to palm oil with Malaysia, which is $85-90 \%$ of the total world palm oil yield. With so much information on Indonesian oil palm on Twitter so that it can be used to see public opinion about Indonesian oil palm. In this study managed to collect tweet data from 28 August 2019 to 21 June 2018 resulting in 1015 tweets. In order to see the tweets, the categories are categorized into positive, negative and neutral, then the tweets are classified using the naïve Bayes method and using the Orange tools. Meanwhile, to do data crawling using Twitter API facilities. Of the 1015 data tweets $70 \%$ is used for training data and $30 \%$ for testing data. In the application of calisification with the naive bayes method it produces an average accuracy of $0.83337 \%$ for the average of all categories, for precision obtains $0.80303 \%$ for the average of all categories, and for recall produces $0.90853 \%$ for all average categories. With this level of accuracy the Naïve Bayes method works in line with expectations.
\end{abstract}

Keywords - Naïve Bayes, Indonesian Palm Oil, Opinion, Classification 


\section{PENDAHULUAN}

$\mathrm{I}^{\mathrm{n}}$ ndonesia mempunyaigeografis yang sangat efektif terhadap sumberdaya alam. Sehingga Indonesia merupakan negara yang kaya akan sumberdaya alamnya. Merajut kepada data Badan Pusat Statistika, Indonesia memiliki tiga sektor yang ikutan didalam kemajuan ekonominya berupa sektor pertanian, perdagangan dan sekitor industri. Pertanian dapat dibagi dalam empat kategori yaitu, Pertanian Hortikultura, Perkebunan, Kehutanan dan Peternakan [1]. Kepala Sawit adalah salah satu hasil pertanian dari sawit. Minyak kelapa sawit merupakan yang paling banyak digunakan di dunia. Dengan hasil dari minyak sawit ini dapat diproduksi untuk bermacam makanan, kosmetik, hasil kebersihan dan dengan penemuan canggih dapat sebagai sumber biofuel atau lebih dikenal dengan biodiesel. Indonesia merupakan negara yang mendominasi produksi hasil pertanian sawitnya dengan menyumbang $85-90 \%$ dari semua hasil produksi minyak sawit dunia bersama dengan Malaysia [2]. Pada tiga tahun terakhir Indonesia telah mengekspor kelapa sawit yaitu, 2018 dengan hasil 41.67 juta ton, 2017 dengan hasil 38.17 juta ton dan 2016 dengan hasil 27.0 juta ton dengan hasil yang diperoleh meningkatkan devisa negara [3].

Twitter merupakan salah satu dari sekian banyak media egati yang difungsikan sebagai pemasaran produk, dimana twitter sebagai media egati yang sangat popular setelah Facebook, Instagram dan lain-lain. Pada tahun 2016 Indonesia memiliki pengguna aktif sebanyak 24.340 juta orang. Twitter dapat menampung sebanyak 280 karakter, kemudian diolah menjadi sebuah statement [4]. Dewasa ini media twitter dimanfaatkan sebagai perluasan bisnis, dimana pengguna bisa menemukan pelaku bisnis lain sehingga bisa menjadi teman atau pengikut (followers) dan tentu bisa saling berinteraksi.

Twitter menyediakan fasilitas-fasilitas agar bias dimanfaatkan oleh para pengguna akun twitter, salah satunya adalah fasilitas retweet. Banyaknya retweet atau komentar masyarakat tentang perkembangan maupun penyebaran informasi sektor pertanian di twitter, retweet tersebut dapat diolah kemudian disajikan dalam bentuk informasi sehingga dapat mengetahui pendapat masyarakat tentang perkembangan sektor pertanian. Retweet dari followers akan dapat mempengaruhi pola egati dari followers sehingga bias membuat retweet bisa memungkinkan terjadinya overload retweet. Dengan demikian retweet dapat di klasifikasikan kalimat yang berhubungan dengan retweet perkembangan pada sektor pertanian, sehingga dapat menemukan pola dalam pengelompokan kalimat yang positif, negatif dan netral. Pengumpulan data tweet dari twitter dapat dilakukan dengan menghubungkan Twitter API dan Orange Tools [5].

Berdasarkan penelitian yang telah dituliskan diatas, penelitian ini akan melakukan sebuah dengan klasifikasi opini data pada twitter. Data yang telah diperoleh dari twitter akan diproses dengan textmining untuk menghindari data yang tidak diinginkan, setelah itu dikelompokan data tweet atau komentar berdasarkan klasifikasi positif, negatif dan netral. Pengelompokan ini menggunakan perbandingan metode Nä̈ve Bayes.

\section{LANDASAN TEORI}

\subsection{Text Mining}

Text mining adalah proses mengektrak informasi yang berguna dari sekumpulan dokumen dari waktu kewaktu melalui identifikasi pola yang menarik [4]. Text mining adalah proses penemuan informasi baru dengan mengekstrak pola secara otomatis dari berbagai sumber teks [6].

Text mining mempunyai beberapa tingkatan fungsional, text mining mengikuti model yang telah disediakan oleh beberapa aplikasi data mining sehingga dapat terbagi menjadi empat 
tingkatan fungsional utama, yakni preprocessing task, processed document collection, dan core mining operations [4]. Tingkatan arsitektur dari text mining dapat dilihat pada gambar. 1.

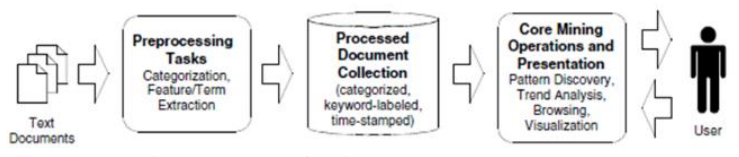

Gambar 1. Arsitektur Text Mining [4].

\subsection{Preprocessing}

Text preprocessing merupakan awal mula dari text mining. Tujuan dari text preprocessing adalah membersihkan data dari noise sehingga data menjadi lebih kecil dan lebih terstruktur. Berikut ini adalah tahapan proses dari text preprocessing [4].

\section{a. Tokenizing}

Tokenizing merupakan proses pemecahan teks menjadi kata tunggal dan menghapus tanda baca serta angka, sesuai dengan kamus yang telah ditentukan.

b. Stopword Removing

Stopword removing merupakan proses menghilangkan kata tidak penting dalam teks. Hal ini dilakukan untuk memperbesar akurasi dari pembobotan. Dalam penelitian ini Stopword removing digunakan untuk menghilangkan kata-kata seperti: dan, atau, mungkin, ini, itu dan sebagainya merupakan kata yang dapat dihilangkan.

c. Stemming

Stemming merupakan perubahan berbagai kata imbuhan menjadi sebuah kata dasar. Dalam penelitian ini kata imbuhan yang dihilangkan adalah teks yang berbahasa Inggris, dikarenakan teks bahasa Inggris memiliki bentuk lampau.

\subsection{Nä̈ve Bayes}

Naïve Bayes adalah salah salah satu algoritma klasifikasi yang ditemukan oleh Tomas Bayes. Klasifikasi adalah proses untuk memperoleh aturan atau model yang dapat mengklasifikasikan data baru yang belum pernah dipelajari dengan mempelajari sekumpulan data yang lama. Nä̈ve Bayes adalah algoritma klasifikasi probabilistik yang sederhana berdasarkan Teorema Bayes [7]. Prinsip umumnya adalah mengasumsikan bahwa nilai suatu atribut tidak bergantung dan mempengaruhi atribut yang lainnya. Model Nä̈ve bayes memungkinkan setiap atribut memiliki kontribusi yang sama terhadap keputusan akhir dan komputasinya lebih efisien bila dibandingkan dengan algoritma pengklasifikasi teks lainnya. Model yang diperoleh dari proses training berisikan kumpulan konstanta untuk setiap data train. Model tersebut akan digunakan pada data testing untuk melihat seberapa akurat model yang telah diperoleh [8]. Nä̈ve bayes menjumlahkan frekuensi dan kombinasi nilai dari dataset untuk menghitung probabilitas. Probabilitas dihitung dengan menggunakan persamaan 1 [7].

$$
P(H \mid X)^{\wedge}=(P(X \mid H) . P(H)) /(P(X))(1)
$$

Pada persamaan diatas adalah:

$\mathrm{X} \quad=$ Data dengan class yang belum diketahui

$\mathrm{H} \quad=$ Hiptotesis data merupakan suatu class spesifik

$\mathrm{P}(\mathrm{H} \mid \mathrm{X})^{\wedge}=$ Probabilitas hipotesis berdasar kondisi

$\mathrm{P}(\mathrm{H}) \quad=$ Probabilitas hipotesis

$\mathrm{P}(\mathrm{X} \mid \mathrm{H})=$ Probabilitas berdasarkan kondisi pada hipotesis

$\mathrm{P}(\mathrm{X}) \quad=$ Probabilitas $\mathrm{H}$

Irsyad et al, [Klasifikasi Opini Terhadap Pertanian Sawit (Palm Oil) Indonesia Menggunakan Naïve Bayes] 


\subsection{Sentiment Analysis}

Analisis sentimen, juga disebut penambangan opini, adalah bidang studi itu menganalisis pendapat, sentimen, evaluasi, penilaian, sikap, dan emosi terhadap entitas seperti produk, layanan, organisasi, individu, masalah, peristiwa, topik, dan atributnya. Itu mewakili besar ruang masalah. Ada juga banyak nama dan tugas yang sedikit berbeda, misalnya, analisis sentimen, penambangan opini, ekstraksi pendapat, sentimen penambangan, analisis subjektivitas, analisis pengaruh, analisis emosi, peninjauan penambangan, dan lain-lainya. Namun, sekarang semuanya berada di bawah payung analisis sentimen atau penambangan opini. Sementara di industri, analisis sentimen jangka lebih umum digunakan, tetapi di akademisi baik analisis sentimen dan penambangan opini sering digunakan.[9]

\subsection{Twitter Rest API}

Twitter adalah jejaring sosial populer di mana pengguna dapat berbagi pesan singkat seperti SMS (Short Message Service) yang disebut tweet. Pengguna berbagi pemikiran, tautan, dan gambar di twitter, jurnalis mengomentari secara langsung, perusahaan mempromosikan produk, dan terlibat dengan pelanggan. Berbagai cara dalam menggunakan twitter, dengan 500 jutaan tweet perhari, ada banyak data untuk dianalisis dan dimainkan. Twitter Rest APIs menyediakan akses terprogram untuk membaca dan menulis data twitter. Buat tweet baru, baca profil penulis dan data pengikut, dan banyak lagi. REST API mengidentifikasi aplikasi Twitter dan pengguna yang menggunakan Oauth; tanggapan tersedia di JSON [10].

\section{METODE PENELITIAN}

Gambaran umum dalam proses penelitian dapat dilihat pada gambar 2 sebagai berikut:

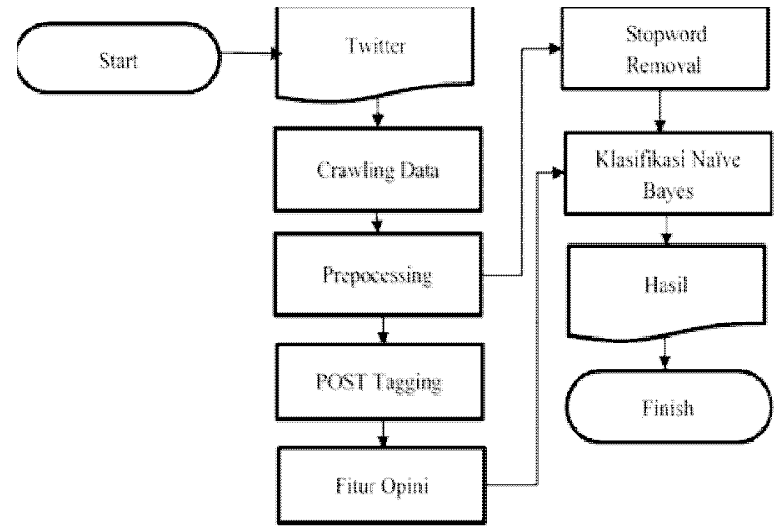

Gambar 2. Gambaran Umum Penelitian

Skenario dari penelitian ini adalah sebagai berikut:

a) Tools Orange akan menerima inputan berupa dataset twitter. Data tersebut diambil berdasarkan inputan tweet dari akun "@infosawit”.

b) Melakukan preprocessing terhadap dataset agar dapat memenuhi klasifikasi dan mempermudah dalam memproses data.

c) POST Tagging berfungsi sebagai pencarian 233 egati opini. POST Tagging berfungsi juga sebagai ektraksi fitur opini. POST Tagging dilakukan secara manual dalam menentukan fitur opini masuk kategori positif, 233 egati atau netral.

d) Setelah fitur opini didapatkan, maka akan dilakukan langkah selanjutnya dengan menggunakan stop word removal. Stop word removal sendiri berfungsi untuk menghapus kata-kata yang sering muncul akan tetapi tidak memiliki makna dalam penelitian ini. 
e) Proses selanjutnya adalah melakukan pengklasifikasian negatif data dengan menggunakan Nä̈ve Bayes.

Dataset yang digunakan dalam penelitian ini merupakan opini-opini masyarakat tentang sawit yang ada di Indonesia pada saat sekarang. Algoritma yang digunakan untuk klasifikasi adalah Nä̈ve Bayes dengan menggunakan tools Orange [5].

\section{a. Crawling Data Tweets}

Dataset yang digunakan dalam penelitian ini adalah data dari berbagai akun yang selalu mentweetkan pertanian dan sawit. Dataset yang diambil menggunakan Application Programming Interface (API) Twitter menggunakan Tools Orange.

Keyword yang digunakan adalah pertanian, penarikan data mulai dari tanggal 28 Agustus 2019 sampai dengan 21 Juni 2018. Dari hasil crawling data diperoleh tweet sebanyak 1015 tweet. Adapun hasil dari perolehan crawling data adalah:

Tabel 1. Hasil Crawling dari Twitter

\begin{tabular}{|c|c|}
\hline No & Komentar Opini \\
\hline 1. & $\begin{array}{l}\text { RT @ infosawit: Petani Sawit Minta Jokowi Serius Tingkatkan Kualitas } \\
\text { SDM Petani } \\
\text { \#beritasawot \#sawit \#palmoil \#infosawit \#Smallholders @ InfoSawit }\end{array}$ \\
\hline 2. & $\begin{array}{l}\text { Harga TBS Sawit Jambi Periode } 23-29 \text { Agustus } 2019 \text { Naik Rp 39,2/Kg } \\
\text { \#Beritasawit \#sawit \#palmoil \#infosawit \#HargaTBS \#HargaSawit } \\
\text { \#CPOPricehttps://t.co/dpNvkLA8tR }\end{array}$ \\
\hline 3. & $\begin{array}{l}\text { Perkuat Pasar Sawit Domestik, Hilangkan Ketergantungan Pasar Ekspor } \\
\text { \#beritasawit } \quad \text { \#sawit }\end{array}$ \\
\hline 4. & $\begin{array}{l}\text { Presiden Awasi Langsung Mandatori Biodiesel Sawit (B30) di Tahun } \\
2020 \\
\text { \#Beritasawit \#sawit \#palmoil \#infosawit \#aprobi \#biodiesel } \\
\text { @jokowihttps://t.co/16drVJK190 }\end{array}$ \\
\hline 5. & $\begin{array}{l}\text { Harga TBS Sawit Kaltim Periode Agustus } 2019 \text { Turun Rp 24,01/Kg } \\
\text { \#beritasawit } \quad \text { \#Sawt }\end{array}$ \\
\hline 6. & $\begin{array}{l}\text { Harga TBS Sawit Jambi Periode 12-18 Juli } 2019 \text { Turun Rp 21,31/Kg } \\
\text { \#beritasawit \#sawit \#palmoil \#infosawit \#hargaTBS \#HargaSawit } \\
\text { @PerekonomianRI @KeuanganRIhttps://t.co/HieqAzbgPn }\end{array}$ \\
\hline 7. & $\begin{array}{l}\text { Harga TBS Sawit Riau Periode 3-9 Juli } 2019 \text { TurunRp. 44,64/Kg } \\
\text { \#beritasawit \# \#Sawit \#palmoil \#infosawit \#hargatbs } \\
\text { \#hargasawithttps://t.co/FijqgQZWKO }\end{array}$ \\
\hline 8. & $\begin{array}{l}\text { RSPO Resmi Luncurkan Pedoman "Upah Hidup Layak" untuk Para } \\
\text { Pekerja Sawit } \\
\text { \#beritasawit \#sawit \#palmoil \#infosawit \#rspo \#sustainable \#sustainability } \\
\text { https://t.co/lpmPAGHelL }\end{array}$ \\
\hline
\end{tabular}

\section{b. Preprocessing}

Pada tabel 1 diatas telah didapatkan hasil dari crawling data dari twitter, maka selanjutnya kita akan ketahap preprocessing agar data-data yang telah crawling tersebut dapat menjadi terstruktur. Berikut ini adalah tahapan dari proses preprocessing:

\section{- Tokenizing}

Irsyad et al, [Klasifikasi Opini Terhadap Pertanian Sawit (Palm Oil) Indonesia Menggunakan Nä̈ve Bayes] 
Sebagaimana telah dijelaskan di atas, Tokenizing merupakan proses pemecahan teks menjadi kata tunggal dan menghapus tanda baca serta angka, sesuai dengan kamus yang telah ditentukan.

Maka berdasarkan dataset di twitter, pada umumnya pemilik akun hanya menggunakan kata-kata baku bahkan menggunakan kata-kata gaul untuk membuat sebuah ciutan atau tweet. Tugas pada Tokenizing ini adalah mengubah kata-kata baku tersebut sehingga lebih mudah dimengerti.

Tabel 2. Contoh Tokenizing

\begin{tabular}{|l|}
\hline \multicolumn{2}{|c|}{ Komentar Opini } \\
\hline Urai Masalah Tata Ruang, Diusulkan ATR/BPN \\
Diberikan Kewenangan Lebih \\
\#beritasawit \#sawit \#palmoil \#infosawit @ Atr_BPN \\
@ KemenkoRIhttps://t.co/7EmyufmdMd \\
\hline Menjadi \\
\hline Urai Masalah Tata Ruang Diusulkan ATR atau BPN \\
Diberikan Kewenangan Lebih \\
\hline
\end{tabular}

- $\quad$ Stopword Removing

Stopword removing merupakan proses menghilangkan kata tidak penting dalam teks. Hal ini dilakukan untuk memperbesar akurasi dari pembobotan. Dalam penelitian ini Stop wordremoving digunakan untuk menghilangkan kata-kata seperti: dan, atau, mungkin, ini, itu dan sebagainya merupakan kata yang dapat dihilangkan.

Tabel 3. Contoh Stop Removing

\begin{tabular}{|l|}
\hline \multicolumn{1}{|c|}{ Komentar Opini } \\
\hline $\begin{array}{l}\text { Urai Masalah Tata Ruang Diusulkan ATR atau BPN } \\
\text { Diberikan Kewenangan Lebih }\end{array}$ \\
\hline \multicolumn{1}{|c|}{ Menjadi } \\
\hline $\begin{array}{l}\text { Urai Masalah Tata Ruang usul ATR BPN beri wewenang } \\
\text { Lebih }\end{array}$ \\
\hline
\end{tabular}

- Post Tagging Tweet

Selanjutnya adalah melakukan pelabelan secara manual dari beberapa proses yang telah diciptakan tadi. Dengan adanya sebuah label maka tweet akan mudah dikelompokan, adapun label yang digunkan sebanyak tiga label yakni Positif, Negatif dan Netral.

Tabel 4. Contoh Post Tagging

\begin{tabular}{|c|l|l|}
\hline No & \multicolumn{3}{|c|}{ Komentar Opini } & Tagging \\
\hline \multirow{2}{*}{ 1. } & $\begin{array}{l}\text { Urai Masalah Tata Ruang } \\
\text { usul ATR BPN berikan } \\
\text { wewenang Lebih }\end{array}$ & Netral \\
\hline \multirow{2}{*}{ 2. } & $\begin{array}{l}\text { Harga TBS Sawit Riau } \\
\text { Periode 21 sampai 27 } \\
\text { Agustus Naik Rp 47,75/Kg }\end{array}$ & Positif \\
\hline
\end{tabular}




\begin{tabular}{|c|l|c|}
\hline 3. & $\begin{array}{l}\text { BPK Temukan Sejumlah } \\
\text { Pelanggaran Izin Sawit }\end{array}$ & Negatif \\
\hline 4. & $\begin{array}{l}\text { Sawit Watch: Pemerintah } \\
\text { Mesti Tegas Atasi Karhutla }\end{array}$ & Positif \\
\hline 5. & $\begin{array}{l}\text { 2023 RSPO Targetkan } \\
\text { Produksi Minyak Sawit } \\
\text { Berkelanjutan 23 Juta Ton }\end{array}$ & Positif \\
\hline
\end{tabular}

Setelah preprocessing dilaksanakan berdasarkan point-point diatas tidak seluruh data yang akan digunakan akan tetapi ada beberapa data digunakan dan ada data yang di simpan atau tidak digunakan. Adapun data yang tidak digunakan seperti tweet yang mengandung unsure emoticon, url, retweet, gambar dan video [5]. Hasil dari crawling data terdapat data sebanyak 1015 tweet. Untuk pengklasifikan data kelas positif adalah 520 data, kelas negatif 218 data dan kelas netral sebanyak 276 data.

Tweet yang telah didapatkan maka akan dibagi menjadi dua data yakni, data training sebanyak 711 data tweet dari $70 \%$ crawling data dan untuk data testing sebanyak 304 data tweet dari $30 \%$ crawling data. Maka dari itu dapat kita lihat pada tabel 5.

Tabel 5. Data Training dan Testing

\begin{tabular}{|c|c|c|c|}
\hline Data & Negatif & Netral & Positif \\
\hline Training & 200 & 134 & 377 \\
\hline Testing & 87 & 70 & 146 \\
\hline
\end{tabular}

Untuk mengukur keakuratan dari hasil porses data training dan data testing maka akan diujikan untuk mengukur dari keakuratan data tersebut. Untuk hasil data testing akan menghasilkan confution matrix. Hasil dari confution matrix dapatlah nilai akurasi, precision dan recall.

Akurasi tersebut dapat dihitung dengan menggunakan persamaan 2.

$$
\text { Akurasi }=\frac{T P+T N}{T P+T N+F P+F N}
$$

Untuk menghitung precision menggunakan persamaan 3.

$$
\text { Precision }=\frac{T P}{T P+F P}
$$

Untuk menghitung nilai recall dapat dilihat pada Persamaan 4.

Dimana:

$$
\text { Recall }=\frac{T P}{T P+F N}(4)
$$

$\mathrm{TP}=$ True Positif Count .

$\mathrm{TN}=$ True Negative Count .

$\mathrm{FP}=$ False Positive Count .

$\mathrm{FN}=$ False Negative Count . 


\section{HASIL DAN PEMBAHASAN}

Setelah preprocessing selesai dilakukan, selanjutnya kita akan mengambil data dari wordcloud sehingga dapat diketahui opini yang paling dominan pada tweet. Sehingga hasil dari wordcloud nantinya dapat digunakan pengkategorian yakni, positif, negatif dan netral. Hasil dari wordcloud dapat dilihat pada gambar 3 berikut ini.

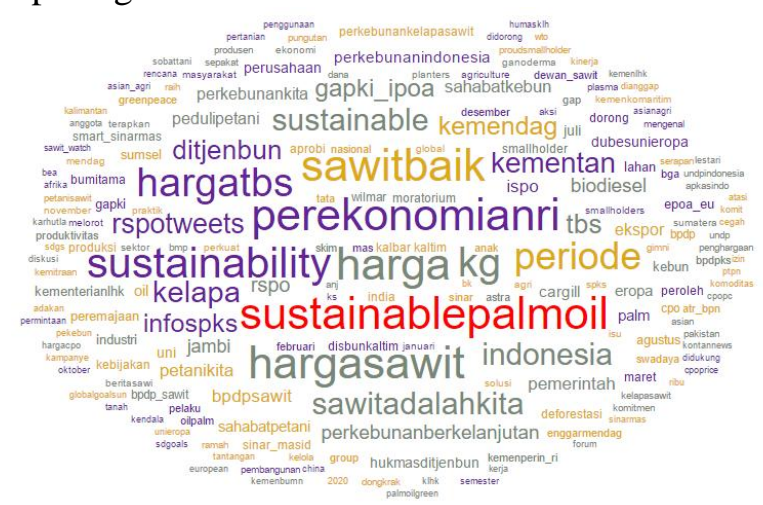

Gambar 3. Hasil Wordcloud

Dari hasil wordcloud tersebut, terdapat 8 kata dominan dari setiap masing-masing opini yang sudah melalui klasifikasi yakni:

Tabel 6. Wordcloud yang Dominan

\begin{tabular}{|l|l|}
\hline Weight & Word \\
\hline 180 & Harga \\
\hline 177 & Sustainable Palm Oil \\
\hline 159 & Perekonomian RI \\
\hline 152 & Sawit Baik \\
\hline 145 & Harga Sawit \\
\hline 134 & Sustain Ability \\
\hline 127 & Harga TBS \\
\hline 90 & Sawit adalah Kita \\
\hline
\end{tabular}

Dari hasil wordcloud diatas maka akan dilakukan pengujian terhadap hasil tweet tersebut. Hasil pengujian dari tweet tersebut terdapat pengkategorian positif 147 data tweet, untuk negatif 87 data tweet dan untuk netral sebanyak 69 data tweet. Hasil pengujian tersebut dapat kita lihat pada tabel 7.

Tabel 7. Pegujian Data Tweet

\begin{tabular}{|c|c|c|c|}
\hline Ketegori & Negatif & Netral & Positif \\
\hline Negatif & 62 & 1 & 24 \\
\hline Netral & 14 & 22 & 33 \\
\hline Positif & 24 & 31 & 92 \\
\hline
\end{tabular}

Berdasarkan tabel 7 diatas, maka akan direalisasikan menjadi confution matrix sehingga dapat diguanakan untuk menghitung tingkat akurasi, precision dan recall, sehingga menghasilkan setiap kategori yang dapat dilihat pada tabel 7 .

Tabel 8. Hasil Akurasi, Precission dan Recall 


\begin{tabular}{|c|c|c|c|}
\hline Ketegori & Akurasi & Precision & Recall \\
\hline Negatif & 0.87129 & 0.64935 & 0.98850 \\
\hline Netral & 0.77723 & 0.80521 & 0.80232 \\
\hline Positif & 0.85149 & 0.95454 & 0.93478 \\
\hline Average & 0.83337 & 0.80303 & 0.90853 \\
\hline
\end{tabular}

Dari hasil tabel 8 diatas bahwasan kategori yang memiliki tingkat akurasi yang lebih tinggi adalah negative dengan nilai $0.871 \%$, untuk kategori positif $0.851 \%$ dan untuk kategori yang rendah adalah netral $0.777 \%$, sehingga mendapatkan nilai rata-rata dari seluruh akurasi adalah $0.833 \%$. selisih antara nilai Negatif dan Positif adalah sebanyak 0.02\% dengan hasil selisih yang sedikit dapat dibuktikan terdapat beberapa kesalahan dari tweet, mungkin berupa kata-kata yang sama atau berupa kata-kata singkatan yang sulit didetect oleh tools, sehingga ada kendala dalam melakukan pengkategorian.

\section{KESIMPULAN}

Hasil opini dari masyarakat terhadap sawit Indonesia (Palm Oil) dengan menggunakan dataset pada twitter dengan menerapkan metode naïve bayes dapat menghasilkan tingkatan akurasi $0.83337 \%$ untuk rata-rata seluruh kategori, untuk precision memperoleh $0.80303 \%$ untuk rata-rata seluruh kategori, dan untuk recall menghasilkan $0.90853 \%$ untuk seluruh ratarata kategori. Dengan hasil ini tools orange sudah mulai berjalan dengan baik dari pada sebelumnya.

Dari hasil opini yang sering muncul untuk dataset dari tweet adalah masalah harga. Sustainable Palm Oil, Perekonomian RI, Sawit Baik, Harga Sawit, Sustainability, harga TBS dan Sawit adalah kita.

\section{SARAN}

Penelitian ini diharapkan dapat dikembangkan dengan menggunakan tools-tols yang lain sehingga menghasilkan hasil yang lebih baik lagi.

\section{UCAPAN TERIMA KASIH}

Terimakasih kepada TIM LPPM STMIK Global Informatika MDP dan Kemenristek DIKTI atas dukungannya dalam penelitian ini.

\section{DAFTAR PUSTAKA}

[1] B. P. Statistik, “www.bps.go.id," 522 2018. [Online]. Available: https://www.bps.go.id/pressrelease/2018/02/05/1519/ekonomi-indonesia-triwulan-iv-2017-tumbuh-5-19-persen.html. [Accessed 108 2018].

[2] Indonesia Invesment, "www.indonesia-investment.co"m 29082019 [online]. Available: https://www.indonesia-investments.com/id/bisnis/komoditas/minyak-sawit/item166?. 
[3] Gatra,"www.gatra.com", $29 \quad 8 \quad 2019 \quad$ [Online]. Available: https://www.gatra.com/detail/news/416887/economy/ekspor-minyak-sawit-indonesia-capai296-juta-ton-pada-maret-2019. [Accessed 2908 2019].

[4] M. Rani and A. J 2016, "Twitter Data Predicting Geolocation Using Data Mining Techniques,"International Journal of Innovative Research in Computer, Vol. 4, No. 6, p. 10446.

[5] Hafiz I, . M. Rizky 2019, "Klasifikasi Opini Masyarakat Terhadap Jasa ISP MYRepublic dengan Naïve Bayes,"Jurnal JNTETI, Vol. 8, No. 1.

[6] A. Saleh 2015, “Implementasi Metode Klasifikasi Nä̈ve Bayes Dalam Memprediksi Besarnya Penggunaan Listrik Rumah Tangga, ”Creative Information Technology Journal, Vol. 2, No. 3, pp. 207-2017.

[7] S. Ting, A. H. Tsang and W. H. Ip 2011, “Is Nä̈ve Bayes a Good Classifier for Document Classification?, "International Journal of Software Engineering and its Applications, Vol. 5, No. 3, p. 398.

[8] M. S. Kini, Devi, D. P.G and N. Chiplunkar 2015, "Text mining Approach to Classify Technical Research Document using Nä̈ve Bayes," International Journal of Advanced Research in Computer and Communication Engineering, Vol. 4, No. 7, pp. 386-391.

[9] A. Valdivia, M. V. Luzón and F. Herrera 2017, “Sentiment analysis in tripadvisor,"IEEE Intelligent Systems, Vol. 4, No. 72-77, p. 32.

[10] S. Budi 2017, “Text Mining untuk Analisis Sentimen Review Film Menggunakan Algoritma KMeans, "Techno.COM, Vol. 16, No. 1, pp. 1-8. 